BMJ Open

Diabetes

Research

\& Care

\title{
Feasibility of computer-generated telephonic message-based follow-up system among healthcare workers with diabetes: a randomized controlled trial
}

\author{
Mahima Sadanshiv (D) , ${ }^{1}$ Lakshmanan Jeyaseelan, ${ }^{2}$ Henry Kirupakaran, ${ }^{3}$ \\ Vikas Sonwani, ${ }^{4}$ Thambu David Sudarsanam ${ }^{5}$
}

To cite: Sadanshiv M, Jeyaseelan L, Kirupakaran $\mathrm{H}$, et al. Feasibility of computergenerated telephonic message-based follow-up system among healthcare workers with diabetes: a randomized controlled trial. BMJ Open Diab Res Care 2020;8:e001237. doi:10.1136/ bmjdrc-2020-001237

- Additional material is published online only. To view, please visit the journal online (http://dx.doi.org/10.1136/ bmjdrc-2020-001237).

Received 31 January 2020 Revised 8 May 2020 Accepted 18 May 2020
Check for updates

(c) Author(s) (or their employer(s)) 2020. Re-use permitted under CC BY-NC. No commercial re-use. See rights and permissions. Published by BMJ.

For numbered affiliations see end of article.

Correspondence to Dr Mahima Sadanshiv; msadanshiv@gmail.com

\section{ABSTRACT}

Introduction To assess the feasibility of computergenerated educational messaging system in healthcare workers of a tertiary care hospital. The secondary objectives were glycemic control, patient satisfaction and adherence to lifestyle modifications.

Research design and methods Single-center parallelgroup open-labeled randomized controlled trial with computer generated block randomization.

Setting Healthcare workers with diabetes working in Christian Medical College Vellore, Tamil Nadu.

Participants 431 assessed, 341 met the selection criteria, 320 participants were randomized and 161 were taken into intervention arm and 159 in the control arm.

Intervention Computer-generated short message service (SMS) based on transtheoretical model of behavioral change, 2 messages per week for 3 months, along with standard of care diabetic care. Messages had educational material regarding healthy eating habits and exercise and these messages were sent twice weekly. The messages were scheduled via an automatic calendar in a way that each subject in the intervention arm received 15 educational messages per month.

Control group received only standard of care diabetic care which included dietary advice, exercise regimen and diabetic medications under supervision of their physician every 3 months.

Follow-up 6 months.

Results $95.65 \%$ of people in the intervention arm ( $n=154)$ received regular messages, out of which $93.17 \%$ read the messages regularly. $80.12 \%$ acted on the messages. 93.17\% felt more satisfied with their healthcare. While both groups showed improvement in body mass index (BMI) and hemoglobin A1c (HbA1c), the difference was greater in the intervention with regard to both decrease in BMI $(-0.6, p<0.001)$ and HBA1c $(-0.48$, $p<0.001$ ).

Conclusions SMS-based education system is feasible in improving healthcare among healthcare workers with diabetes. It improves patient satisfaction, adherence and improves healthcare among individuals with diabetes by decreasing their BMl and decreasing HbA1c.

\section{INTRODUCTION}

The burden of diabetes in India is estimated at $7.3 \%$ with lower socioeconomic strata

\section{Significance of this study}

What is already known about this subject?

- Telephonic messages have been shown to reduce hemoglobin A1C (HbA1C) in subjects with diabetes.

- An umbrella systematic review suggests that most studies included were of poor methodological quality.

What are the new findings?

- Healthcare workers with diabetes have a high level of acceptance of educational telephonic messages on diabetes and these lead to reduction in body mass index (BMI) and HbA1C.

- Educational telephonic messages on diabetes have a high level of acceptance among healthcare workers with diabetes.

- They improve healthcare workers' knowledge about diet, exercise and healthy lifestyle.

- These messages given for 3 months reduce BMI as well as $\mathrm{HbA1c}$ at 6 months.

How might these results change the focus of research or clinical practice?

- In clinical practice, healthcare workers with diabetes may benefit from well-planned telephonic messages designed to increase knowledge and change behavior.

- Future research should look at reductions in diabetic complications as well as measures of compliance to these messages.

impacted more. ${ }^{1}$ There are some studies which suggest that in low-income and middleincome countries people with higher education have higher risk. ${ }^{2}$ The benefits of tight blood sugar control among diabetics are well described. However, changing patient behavior with respect to lifestyle modification is not so easy. Healthcare workers, defined by $\mathrm{WHO}$ as all people engaged in actions whose primary intent is to enhance health, ${ }^{3}$ are particularly lax when it comes to their own health. ${ }^{4}$ 


\section{BACKGROUND AND RATIONALE}

Previous trials have used telephonic messages to change patients' behavior using the transtheoretical model. ${ }^{56}$ This has been tried in treatment of hypertension ${ }^{7}$ as well as prevention of diabetes. ${ }^{8-12}$

Three systematic reviews have looked at the effect on diabetes. A network meta-analysis ${ }^{13}$ and an umbrella review ${ }^{14}$ both suggested reduction in hemoglobin A1c (HbAlc), while another also found reduction in HbAlc but no change in clinical outcomes. ${ }^{15}$ Overall, they found the studies of low methodological quality at best. ${ }^{14}$

Thus, there is a need for well-conducted randomized controlled trials (RCTS) on the use of telemedicine among healthcare workers with diabetes. In Changing Lifestyle in Diabetics (CLIDS) via short message service (SMS) trial, our hypothesis was that SMS messages might be helpful in improving diabetic control status, quality of life and sense of well-being among the healthcare workers as well. Changing behavior has been described as being in the following stages in the transtheoretical model precontemplation, contemplation, preparation, action and maintenance. If the SMS messages could help in sustained behavior change that could lead to better sugar control and ultimately better clinical outcomes. Our aim was to assess the feasibility of this computerbased messaging among healthcare workers with diabetes of a tertiary care hospital.

\section{OBJECTIVES}

\section{Primary objective}

To assess the feasibility of computer-generated educational messaging system among healthcare workers of tertiary care hospital. The primary outcome of assessment was the percentage of users who received, read and acted on the SMS at 6 months.

\section{Secondary objectives}

Glycemic control: HbA1c at the end of 6 months.

Patient satisfaction and adherence to lifestyle modifications: to assess the patient satisfaction and adherence to lifestyle behavioral changes.

\section{STUDY DESIGN}

CLIDS was a single-center, two-arm, parallel-group, openlabeled randomized controlled trial to determine the feasibility of use of telephonic messages in the treatment of diabetes among healthcare workers.

\section{MATERIALS AND METHODOLOGY}

The study was conducted in our university medical college hospital in South India. The hospital has over 9000 employees among whom are doctors, nurses, allied health professional, administrative and technical support staff.

The randomization code was developed by the department of biostatistics using SAS software. The block randomization was done with the blocks of $2(30 \%)$, blocks of $4(30 \%)$ and blocks of $6(60 \%)$. The codes were given to the principal investigator in sequentially labeled sealed opaque envelopes to randomly allocate patients (1:1) to individually tailored mobile phone messaging in addition to standard care or to a control group that received standard care alone.

The list of existing healthcare workers with type 2 diabetes was obtained from the staff health service. Some participants were newly diagnosed during the course of the study and were also recruited. The study protocol was clearly explained, following which a written informed consent was taken to participate in the study trial. The mobile phone numbers of the participants was obtained and saved. The trial recruitment started in 2015 January and ended in 2015 August and follow-up continued until 2016 March. Trial was funded by hospitals' internal research fund; they had no role in trial execution, data collection or analysis.

\section{Participants}

Patients aged 18 years or older working as staff in the hospital, diagnosed with type 2 diabetes mellitus. Those who were pregnant had other endocrine disorders associated with diabetes, steroid-induced diabetes (on steroids currently) or who refused consent were excluded.

Baseline demographic details, habits, comorbidities, physical examination including body mass index, waist circumference, diet, exercise and HbAlc were recorded. Waist circumference was measured by trained, certified staff using an anthropometric measuring tape at a horizontal plane that is $1 \mathrm{~cm}$ above the navel. Dietary intake was assessed by the primary investigator. Details regarding the amount in kilocalories of food intake were assessed at each visit. Calculation of energy intake for individual food items was done by the National Institute of Nutrition guidelines for India. The participant was asked to self-categorize the knowledge of their diabetic diet as good, fair, poor and not sure. Physical activity was measured using the Paffenbarger Survey (online supplementary file). The physical activity assessment was done by the primary investigator. These questions allow for calculation of self-reported leisure time, physical activity and kilocalorie expenditure per week.

\section{Intervention}

Educational messages on diet control and exercise were based on the transtheoretical model of human behavior, which has five stages-precontemplation, contemplation, preparation, action and maintenance.

Messages had educational material regarding healthy eating habits and exercise and these messages were sent twice weekly. The messages were scheduled via an automatic calendar in a way that each subject in the intervention arm received 15 educational messages per month (online supplementary file panel 1).

The messages were delivered by a commercial service provider (Unicel Technologies, India). Messages were 
provided only in English language. Each message contained fewer than 160 characters and 60-80 messages were created for transtheoretical model stage and were sent cyclically, such that participants did not receive the same message in a 3-month period (on the basis of them receiving 15 messages per month). The assumption being that the participants moved from a pre-action stage to an action stage. The timing (05:00-08:00 hours or 17:00-20:00 hours) of mobile phone messaging were tailored to the participant's preferences. Participants were informed of the mechanisms for delivery of mobile phone messages. The subjects in the intervention arm received these messages for the first 3 months of the study, following which they also got only the standard care.

In addition to this intervention all patients received standard of care treatment for diabetes.

\section{Control arm}

Those in the control arm received standard of care treatment for diabetes. This included dietary advice initially by a dietician and thereafter by the treating physician at every visit. Exercise advice and medication advice are given at scheduled visits, which are usually at every 3-6 months. Usually HbA1c is tested every 3 months.

\section{Outcome}

The primary objective of the study was assessed at 6 months. This was the feasibility of this computer-generated SMS-based follow-up system for healthcare workers with diabetes, hence the primary outcome was assessed by a questionnaire which included questions regarding the SMS-based system. The secondary outcome included the glycemic control (HbA1c level), patient satisfaction and adherence to lifestyle modifications, assessed with the help of a questionnaire (online supplementary file panel 3).

\section{Sample size calculation and statistical analysis}

As per the study by Ramachandran et al, there was $8 \%$ decreased in the incidence of diabetes in a 2-year follow-up using similar SMS messages. We hypothesized a $10 \%$ reduction in $\mathrm{HbAlc}$ in 6 months. The SD of HbAlc was assessed as 1.5, and with alpha and beta errors of $5 \%$ and $20 \%$, respectively; with two-sided test, we need to study nearly 140 subjects in each arm. Assuming $10 \%$ drop out, we had decided to study 160 subjects in each arm.

Data were collected in a Clinical Research Form (CRF) designed for the study; data were then entered in EpiData V.3.1 and exported to SPSS V.22 for analysis. All analyses were done using intention-to-treat principle.

\section{RESULTS}

\section{Overview of trial conduct}

A total of 431 people were assessed for eligibility from January 2015 to September 2015. One hundred thirtyfive subjects were picked from staff health service, 215 from the individual departments who were already

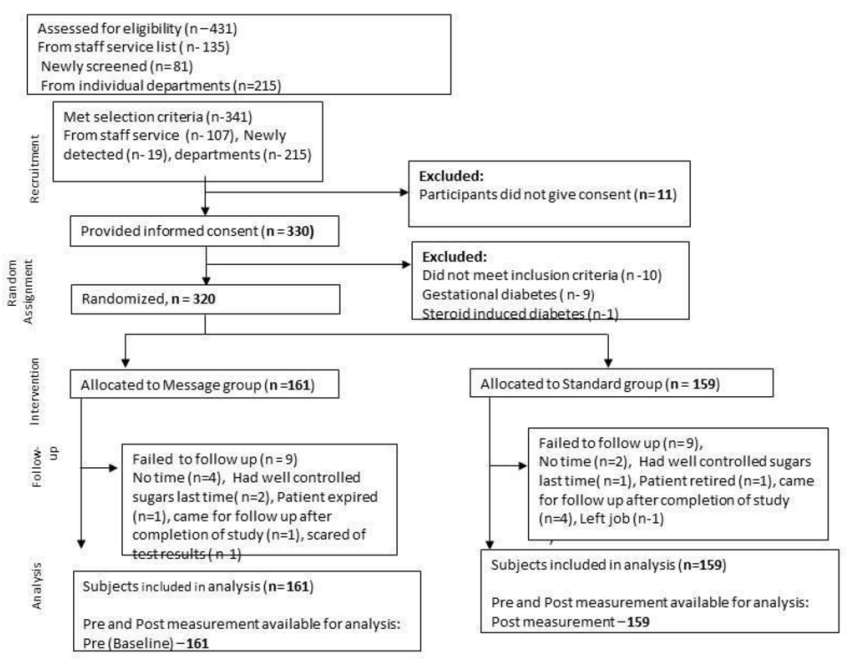

Figure 1 Overview of Consolidated Standards of Reporting Trials.

diagnosed to have diabetes mellitus. Eighty-one subjects were newly screened from individual departments, out of which 19 were found to have diabetes mellitus; they were also assessed. Among all the above-mentioned subjects, 341 met the selection criteria, out of which 11 were excluded since they did not give consent. Three hundred twenty were recruited into the trial, out of which 161 were randomized into the intervention arm and 159 were randomized into the control arm. A total of 18 people failed to follow-up, 9 people in the intervention arm and 9 in the standard arm for which some of them gave lack of time as the reason, few of them mentioned having well-controlled sugars the previous time hence no need of frequently checking sugars and 2 of them retired from the job. Out of these 18, 5 people did follow-up later after the completion of trial. All of them were accounted for the analysis for primary and secondary outcomes (figure 1).

\section{BASELINE CHARACTERISTICS}

The baseline characteristics in both the intervention and standard arm were well matched including the demographic profile, baseline sugar control and associated comorbidities (table 1).

\section{PRIMARY OUTCOMES}

Among the 161 subjects assigned to intervention arm, $95.65 \% \quad(n=154)$ received the SMS via computergenerated software, $4 \%(\mathrm{n}=7)$ did not receive the SMS due to technical issues (table 2). Certain telephonic companies had activated 'DND'-do not disturb services due to which there was a difficulty in sending messages to those subjects.

As seen most read the messages regularly, found the messages useful in improving their knowledge of diabetes and lifestyle changes in diabetes and felt better after receiving the messages. However, only $80 \%$ acted on the messages and followed the lifestyle interventions. 
Table 1 Baseline characteristics

\begin{tabular}{|c|c|c|c|c|c|}
\hline \multirow{2}{*}{ Variable } & & \multicolumn{2}{|l|}{ Intervention } & \multicolumn{2}{|c|}{ Standard } \\
\hline & & $\mathbf{N}$ & $\%$ & $\mathbf{N}$ & $\%$ \\
\hline \multicolumn{2}{|l|}{ Age: mean (SD) } & \multicolumn{2}{|l|}{$48.7(7.4)$} & \multicolumn{2}{|c|}{$47.9(8.0)$} \\
\hline \multicolumn{2}{|l|}{ Years of diabetes: mean (SD) } & \multicolumn{2}{|l|}{$5.3(5.0)$} & \multicolumn{2}{|c|}{$5.0(5.4)$} \\
\hline \multirow[t]{2}{*}{ Sex } & Female & 68 & 42.2 & 76 & 47.8 \\
\hline & Male & 93 & 57.8 & 83 & 52.2 \\
\hline \multirow[t]{7}{*}{ Occupation } & Attendants helpers & 49 & 31.2 & 66 & 42.9 \\
\hline & Technicians & 10 & 6.4 & 10 & 6.5 \\
\hline & Nursing staff & 35 & 22.3 & 36 & 23.4 \\
\hline & Doctors & 0 & 0.0 & 1 & 0.6 \\
\hline & Clerical & 18 & 11.5 & 11 & 7.1 \\
\hline & Administration & 14 & 8.9 & 7 & 4.5 \\
\hline & Others & 31 & 19.7 & 23 & 14.9 \\
\hline \multirow{2}{*}{ Hypertension } & Yes & 56 & 35.0 & 60 & 37.7 \\
\hline & No & 104 & 65.0 & 99 & 62.3 \\
\hline \multirow[t]{2}{*}{ Dyslipidemia } & Yes & 99 & 63.1 & 108 & 69.7 \\
\hline & No & 58 & 36.9 & 47 & 30.3 \\
\hline \multirow[t]{2}{*}{ Coronary artery disease } & Yes & 10 & 6.3 & 18 & 11.3 \\
\hline & No & 148 & 93.7 & 141 & 88.7 \\
\hline \multirow[t]{2}{*}{ Previous stroke } & Yes & 1 & 0.6 & 2 & 1.3 \\
\hline & No & 158 & 99.4 & 157 & 98.7 \\
\hline \multirow[t]{2}{*}{ Chronic kidney disease } & Yes & - & - & - & - \\
\hline & No & 158 & 100.0 & 158 & 100.0 \\
\hline \multirow[t]{2}{*}{ Peripheral vascular disease } & Yes & 1 & 0.6 & 0 & 0.0 \\
\hline & No & 158 & 99.4 & 159 & 100.0 \\
\hline \multirow[t]{2}{*}{ Have you ever visited a dietician } & Yes & 98 & 61.3 & 102 & 64.6 \\
\hline & No & 62 & 38.8 & 56 & 35.4 \\
\hline \multirow[t]{4}{*}{ Your knowledge of diet } & Good & 66 & 42.0 & 51 & 32.5 \\
\hline & Fair & 47 & 29.9 & 54 & 34.4 \\
\hline & Poor & 41 & 26.1 & 46 & 29.3 \\
\hline & Not sure & 3 & 1.9 & 6 & 3.8 \\
\hline \multirow[t]{2}{*}{ Do you exercise regularly } & Yes & 82 & 51.6 & 76 & 48.7 \\
\hline & No & 77 & 48.4 & 80 & 51.3 \\
\hline \multirow{7}{*}{$\begin{array}{l}\text { Frequently do you get your sugars } \\
\text { checked }\end{array}$} & Every month & 4 & 2.5 & 2 & 1.3 \\
\hline & Once in 2 months & 5 & 3.2 & 5 & 3.1 \\
\hline & Once in 3 months & 85 & 53.8 & 86 & 54.1 \\
\hline & Once in 6 months & 23 & 14.6 & 31 & 19.5 \\
\hline & Once a year & 7 & 4.4 & 9 & 5.7 \\
\hline & Not regularly whenever I feel like & 28 & 17.7 & 25 & 15.7 \\
\hline & Never & 6 & 3.8 & 1 & 0.6 \\
\hline
\end{tabular}

None of the subjects expressed any dislike to any part of the intervention. At the end of the study, many expressed happiness at the concern for their care.

With regard to change in HbAlc, weight and body mass index (BMI) after 6 months (table 3), we found was there was improvement in both the groups; however, the intervention arm noticed significant change in outcome as compared with the standard arm. There was a small difference in the percentage of patients who had HbAlc of 7 or less $(53.6 \%$ vs $49.37 \%)$, respectively that was not statistically significant $(\mathrm{p}=0.52)$.

\section{Additional analysis}

As baseline, the mean HbA1c was slightly higher to start with as compared with the standard arm multiple-linear regression analysis was done to see the independent 
Table 2 Assessment of feasibility, adherence and compliance

\begin{tabular}{|c|c|c|}
\hline & Frequency & $\%$ \\
\hline \multicolumn{3}{|c|}{ SMS received } \\
\hline Yes & 154 & 48.13 \\
\hline No & 166 & 51.88 \\
\hline \multicolumn{3}{|c|}{ Did you receive sms regularly } \\
\hline Yes & 154 & 95.65 \\
\hline No & 7 & 4.35 \\
\hline \multicolumn{3}{|c|}{ Did you read the message } \\
\hline Yes & 150 & 93.17 \\
\hline No & 11 & 6.83 \\
\hline \multicolumn{3}{|c|}{ Did you act on the message } \\
\hline Yes & 129 & 80.12 \\
\hline No & 32 & 19.88 \\
\hline \multicolumn{3}{|c|}{ Did you find the messages useful } \\
\hline Yes & 145 & 90.06 \\
\hline No & 16 & 9.94 \\
\hline \multicolumn{3}{|c|}{ Did you feel better after reading messages } \\
\hline Yes & 151 & 93.79 \\
\hline No & 10 & 6.21 \\
\hline \multicolumn{3}{|c|}{$\begin{array}{l}\text { SMS improved the knowledge of diet and exercise in } \\
\text { diabetes }\end{array}$} \\
\hline Yes & 150 & 93.17 \\
\hline No & 11 & 6.83 \\
\hline \multicolumn{3}{|c|}{$\begin{array}{l}\text { Are you more satisfied with Healthcare After the SMS } \\
\text { messages }\end{array}$} \\
\hline Yes & 151 & 93.79 \\
\hline No & 10 & 6.21 \\
\hline
\end{tabular}

predictors of HbAlc at 6 months (table 4 ). After adjusting for the baseline HbAlc and BMI, the intervention was still significantly associated with a decrease in HbAlc at 6 months.

Similar adjusted analysis done for independent predictors of BMI at 6 months revealed that BMI at 6 months associated significantly with the intervention (online supplementary file table 5).

\section{DISCUSSION}

In 'CLIDS' via SMS trial, with regard to the primary outcome of feasibility, we found that this SMS-based education system was feasible in delivering healthcare messages to diabetic healthcare workers of a tertiary level hospital and it improved overall knowledge of diabetic lifestyle and also improved patient satisfaction rates. Literature review on healthcare workers' attitude to illhealth health ${ }^{4}$ and overall health-seeking behavior ${ }^{16}$ may suggest non-compliance, but we found overall high levels of participation and satisfaction with this simple intervention.

We found that both the intervention and the control arm had improvement in their glycemic status in terms of improvement in their weight, BMI and HbAlc; however, the change was more significant in the intervention arm. The magnitude of this reduction is similar to previous systematic reviews. ${ }^{13-15}$ While we did not follow-up patients in the long-term to see changes in clinical outcomes, the enthusiasm for the messages and the intervention on whole give reason to be optimistic.

While many other similar studies have been done worldwide to assess the role of telephonic call or SMS in the care of patients suffering from diabetes mellitus, our study evaluated the feasibility and benefit to healthcare workers. While we did complete sample size of the required healthcare workers, we did have few doctors. This issue of having fewer doctors and patients has been reviewed. ${ }^{16}$ Many felt that they could self-treat themselves, while others felt embarrassed to seek care from peers or had no time. We did not collect data on reasons for refusal to consent.

\section{UNEXPECTED OUTCOMES}

There were no adverse events or unexpected outcomes of the intervention. There was one death in the intervention arm, which was because subject developed communityacquired pneumonia and septic shock, which had no direct or indirect relationship with the intervention.

\section{LIMITATIONS}

DND services by telephone services led to $4 \%$ not receiving the messages. Some hospital employees were

Table 3 Secondary outcomes of change in weight, BMI and $\mathrm{HbA1c}$

\begin{tabular}{|c|c|c|c|c|c|c|}
\hline & & $\begin{array}{l}\text { Mean at baseline } \\
\text { (SD) }\end{array}$ & $\begin{array}{l}\text { Mean at } 6 \\
\text { month (SD) }\end{array}$ & $\begin{array}{l}\text { Mean difference (SD) } \\
\text { (6 months-baseline) }\end{array}$ & $\begin{array}{l}\text { Comparison of mean } \\
\text { change (SE) }(95 \% \mathrm{Cl})\end{array}$ & $P$ value \\
\hline \multirow[t]{2}{*}{ Weight } & Intervention & $69.05(10.26)$ & $67.28(9.82)$ & $-1.84(2.11)$ & $-1.66(0.21)(-2.08$ to -1.25$)$ & $<0.001$ \\
\hline & Standard & $66.52(9.74)$ & $66.35(9.66)$ & $-0.17(1.50)$ & & \\
\hline \multirow[t]{2}{*}{ BMI } & Intervention & $26.53(3.49)$ & $25.90(3.40)$ & $-0.70(0.80)$ & $-0.63(0.08)(-0.79$ to -0.48$)$ & $<0.001$ \\
\hline & Standard & $25.82(3.15)$ & $25.76(3.09)$ & $-0.07(0.58)$ & & \\
\hline \multirow[t]{2}{*}{$\mathrm{HbA1c}$} & Intervention & $7.86(1.48)$ & $7.28(1.14)$ & $-0.54(1.09)$ & $-0.48(0.12)(-0.71$ to -0.25$)$ & $<0.001$ \\
\hline & Standard & $7.37(1.23)$ & $7.31(1.28)$ & $-0.06(0.96)$ & & \\
\hline
\end{tabular}

BMI, body mass index; HbA1c, hemoglobin A1c. 
Table 4 Linear regression analysis for predictors of $\mathrm{HbA1c}$ at 6 months

\begin{tabular}{|c|c|c|c|c|c|c|c|}
\hline & \multicolumn{2}{|c|}{$\begin{array}{l}\text { Unstandardized } \\
\text { coefficients }\end{array}$} & \multirow{2}{*}{$\begin{array}{l}\begin{array}{l}\text { Standardized } \\
\text { coefficients }\end{array} \\
\text { Beta } \\
\end{array}$} & \multirow[b]{2}{*}{$\mathbf{T}$} & \multirow[b]{2}{*}{$P$ value } & \multicolumn{2}{|l|}{$95 \% \mathrm{Cl}$} \\
\hline & Beta & SE & & & & $\begin{array}{l}\text { Lower } \\
\text { bound }\end{array}$ & $\begin{array}{l}\text { Upper } \\
\text { bound }\end{array}$ \\
\hline (Constant) & 1.67 & 0.51 & 0.00 & 3.28 & 0.001 & 0.67 & 2.67 \\
\hline HbA1c baseline & 0.60 & 0.04 & 0.69 & 16.02 & 0.000 & 0.53 & 0.68 \\
\hline BMI baseline & 0.02 & 0.02 & 0.06 & 1.39 & 0.165 & -0.01 & 0.05 \\
\hline $\begin{array}{l}\text { Intervention vs } \\
\text { standard }\end{array}$ & 0.32 & 0.10 & 0.13 & 3.06 & 0.002 & 0.11 & 0.52 \\
\hline
\end{tabular}

BMI, body mass index; HbA1c, hemoglobin A1c.

not well versed with reading English and suggested SMS be sent in the local language. There is no objective way to determine whether subjects who received the SMS have read the messages. We did not collect data on the diabetic medication and changes in regimen or medication compliance and only relied on the randomization to ensure this was similar in both groups.

\section{GENERALIZABILITY}

Healthcare workers world over are likely to be similar in behavior characteristics. However, the acceptability of regular SMS messages and motivation to change may vary based on sociocultural differences. In India and Asia, mobile phone usage is high and SMS is a commonly used cheap and acceptable method of communication. This SMS would be culturally acceptable and very feasible. The ease of use as it requires simple information technology support and low cost are added advantages.

\section{CONCLUSION}

SMS-based education system has been found to be feasible in improving healthcare among healthcare workers with diabetes. It improves patient's knowledge about diet, exercise and healthy lifestyle in diabetes. It improves patient satisfaction about their healthcare. It also improves healthcare among individuals with diabetes by decreasing their BMI and thereby improving their glycemic status.

\section{Author affiliations \\ ${ }^{1}$ General Medicine, Christian Medical College and Hospital Vellore, Vellore, Tamil Nadu, India \\ ${ }^{2}$ Biostatistics, Christian Medical College and Hospital Vellore, Vellore, Tamil Nadu, India \\ ${ }^{3}$ Staff Student Health Service, Christian Medical College and Hospital Vellore, Vellore, Tamil Nadu, India \\ ${ }^{4}$ Padhar Hospital, Betul, Madhya Pradesh, India \\ ${ }^{5}$ Internal Medicine, Christian Medical College and Hospital Vellore, Vellore, Tamil Nadu, India}

Acknowledgements The authors would like to thank the healthcare professional of the institute who generously spent their time with them to take part in this study.

Contributors MS designed the study, conducted data and wrote the manuscript. LJ did the data analysis. HK assisted in data collection. VS sonwanui set up and managed the telemed. TDS helped design the study and edit the manuscript.
Funding The study was funded entirely by funds from the hospital's internal research funds.

Competing interests None declared.

Patient consent for publication Not required.

Ethics approval The study commenced after obtaining the approval from the Christian Medical College, Vellore Institutional review board (online supplementary file) IRB number (FG/9226/12/2014), CTRI number (REF/2015/12/010259).

Provenance and peer review Not commissioned; externally peer reviewed.

Data availability statement Data are available on reasonable request.

Open access This is an open access article distributed in accordance with the Creative Commons Attribution Non Commercial (CC BY-NC 4.0) license, which permits others to distribute, remix, adapt, build upon this work non-commercially, and license their derivative works on different terms, provided the original work is properly cited, appropriate credit is given, any changes made indicated, and the use is non-commercial. See: http://creativecommons.org/licenses/by-nc/4.0/.

ORCID iD

Mahima Sadanshiv http://orcid.org/0000-0003-1244-1981

\section{REFERENCES}

1 Anjana RM, Deepa M, Pradeepa R, et al. Prevalence of diabetes and prediabetes in 15 states of India: results from the ICMR-INDIAB population-based cross-sectional study. Lancet Diabetes Endocrinol 2017;5:585-96.

2 Seiglie JA, Marcus M-E, Ebert C, et al. Diabetes prevalence and its relationship with education, wealth, and BMI in 29 low- and middleincome countries. Diabetes Care 2020;43:767-75.

3 WHO. The World Health Report 2006 - working together for health [Internet]. World Health Organization, 2006. https://www.who.int/ whr/2006/en/

4 Tanksley AL, Wolfson RK, Arora VM. Changing the "Working While Sick" Culture: Promoting Fitness for Duty in Health Care. JAMA 2016;315:603-4.

5 Samuel P, Antonisamy B, Raghupathy P, et al. Socio-Economic status and cardiovascular risk factors in rural and urban areas of Vellore, Tamilnadu, South India. Int J Epidemiol 2012;41:1315-27.

6 Ramachandran A, Snehalatha C, Ram J, et al. Effectiveness of mobile phone messaging in prevention of type 2 diabetes by lifestyle modification in men in India: a prospective, parallelgroup, randomised controlled trial. Lancet Diabetes Endocrinol 2013;1:191-8.

7 Omboni S, Ferrari R. The role of telemedicine in hypertension management: focus on blood pressure telemonitoring. Curr Hypertens Rep 2015;17:535.

8 Anon. Text message program improves outcomes, decreases ED utilization among ED patients with poorly controlled diabetes. ED Manag 2014;26:20-3.

9 Varney JE, Weiland TJ, Inder WJ, et al. Effect of hospital-based telephone coaching on glycaemic control and adherence to management guidelines in type 2 diabetes, a randomised controlled trial. Intern Med J 2014;44:890-7.

10 Berry DC, Neal M, Hall EG, et al. Rationale, design, and methodology for the optimizing outcomes in women with gestational diabetes mellitus and their infants study. BMC Pregnancy Childbirth 2013;13:184. 
11 Kirwan M, Vandelanotte C, Fenning A, et al. Diabetes selfmanagement smartphone application for adults with type 1 diabetes: randomized controlled trial. J Med Internet Res 2013;15:e235.

12 Lawson ML, Cohen N, Richardson C, et al. A randomized trial of regular standardized telephone contact by a diabetes nurse educator in adolescents with poor diabetes control. Pediatr Diabetes 2005:6:32-40.

13 Lee SWH, Chan CKY, Chua SS, et al. Comparative effectiveness of telemedicine strategies on type 2 diabetes management: a systematic review and network meta-analysis. Sci Rep $2017 ; 7: 12680$.
14 Chakranon P, Lai YK, Tang YW, et al. Distal technology interventions in people with diabetes: an umbrella review of multiple health outcomes. Diabet Med 2019;128. doi:10.1111/dme.14156. [Epub ahead of print: 20 Oct 2019].

15 Faruque LI, Wiebe N, Ehteshami-Afshar A, et al. Effect of telemedicine on glycated hemoglobin in diabetes: a systematic review and meta-analysis of randomized trials. CMAJ 2017;189:E341-64.

16 Kay M, Mitchell G, Clavarino A, et al. Doctors as patients: a systematic review of doctors' health access and the barriers they experience. Br J Gen Pract 2008;58:501-8. 